\title{
Influence of Temperature and Relative Humidity on the Photographic Response to $\mathrm{Co}^{60}$ Gamma Radiation*
}

\section{Margarete Ehrlich}

\author{
(January 24, 1961)
}

\begin{abstract}
At relative humidities close to a hundred percent, bare film packets are unsatisfactory for personnel dosimetry, regardless of temperature. Sealed polyethylene bags afford considerable protection from excessive humidity.
\end{abstract}

\section{Introduction}

Fading characteristics of the photographic latent image are known to depend on the type of emulsion, the temperature, humidity, and chemical contamination of the atmosphere, as well as on the type of radiation exposure [1]. ${ }^{1}$ Because of the variety of conditions under which photographic personnel dosimeters are presently used, and because of the long periods of time over which they are carried, a knowledge of the fading characteristics of the photographic latent image is of considerable importance in personnel dosimetry.

Early fading studies performed at the National Bureau of Standards on the latent image formed with X-rays were carried out over a period of only one week; all films were exposed at laboratory temperaatures to low-energy X-radiation and then stored for the prescribed length of time at about $25{ }^{\circ} \mathrm{C}$ and 45 percent relative humidity [2]. More recently, Ziegler and Chleck [3] carried out fading studies over a period of 90 days, on films exposed at laboratory temperatures and stored at temperatures between 27 and $34{ }^{\circ} \mathrm{C}$, either in air without humidity control, or in a dry atmosphere of argon. Tomoda et al. $[4,5]$ did latent-image fading studies on several types of X-ray film exposed at laboratory temperatures and stored up to 30 days at $30^{\circ} \mathrm{C}$ at relative humidities between 40 and 75 percent.

The aim of the present study was to determine the response of one type of the more widely used dosimeter films under conditions simulating as closely as possible the temperatures and relative humidities that may be encountered during its use in personnel dosimetry. The films were used in their original packets, which had been sealed commercially into polyethylene bags. For the irradiation, one set of packets was removed from the polyethylene bags, the other set remained protected. All film packets were exposed to $\mathrm{Co}^{60}$ gamma radiation of low intensity for a period of about 1 month under 1 of 12 different combinations of atmospheric temperature and relative humidity. After completion of the exposures, all film packets were enclosed in polyethylene and placed in a refrigerator. About 5 days later they were developed according to conventional procedure, along with control films exposed at room temperature.

*The work was supported by the U.S. Atomic Energy Commission.

1 Figures in brackets indicate the literature references at the end of this paper.
Tomoda found that different film types behaved similarly under his experimental conditions [5]. The experimental conditions employed here differ from those of Ziegler and Chleck and also from those of Tomoda, who exposed at room temperature and heated the films after exposure. However, it is reasonable to assume that different types of film will also behave similarly under the conditions of the present experiment. Therefore, the results obtained here for one dosimeter film should be applicable to other film types as well.

\section{Experimental Technique}

A sealed $\mathrm{Co}^{60}$ source with an activity of about $50 \mu \mathrm{c}$ was placed in the center of a spiral array of lead-enclosed wooden supports, each holding a sealed glass jar containing a small amount of saturated salt solution that produced a known relative humidity within the jar. Four different relative humidities were obtained by using lithium chloride, magnesium chloride, sodium chloride, and potassium sulfate, listed in the order of increasing values of relative humidities. The exact humidity value for each of the three temperatures used was taken from the data of Wexler and Hasegawa [6]. At the temperatures employed for the experiments, the amount of solutes present in the gaseous phase was negligible.

Each glass jar contained two film packets, one bare and one sealed in a polyethylene bag. The packets were supported by small clamps glued to the inside of the jar lids. The walls of the jars were thick enough to establish electronic equilibrium for $\mathrm{Co}^{60}$ radiation at the inner wall surface. They absorbed about 2 percent of the incident $\mathrm{Co}^{60}$ gamma rays.

A total of 24 jars was used. The source-to-jar distances were chosen in such a way as to yield 5 different film exposures at each of the 4 different relative humidities; also 1 jar at each relative humidity was shielded from the radiation.

The entire setup was placed in a room whose temperature was held as closely as possible at a constant value for 1 month. Ábout 5 days after completion of the exposure, the films were developed in Kodak Liquid X-ray Developer for $5 \mathrm{~min}$ at $20^{\circ} \mathrm{C}$, along with "control films". The control films were exposed at room temperature to the radiation from a stronger $\mathrm{Co}^{60}$ source about 4 days prior to develop- 
ment; all control packets were enclosed in polyethylene and were supported from the lids of dry jars during the exposures which lasted for 1 to $30 \mathrm{~min}$. The same procedure was followed for 3 consecutive months, during which the exposure room was maintained at 3 different temperatures.

\section{Results}

The table shows the net densities (i.e., the densities above base and fog) obtained at the 4 different exposure levels and for each of the 12 exposure conditions; the listed values were taken from curves of the plotted experimental data. The uncertainty in the exposures is estimated to be less than 10 percent, while that in the density readings is less than 0.02 density units. The tabulation enables the reader to plot, for purposes of comparison, one characteristic curve for each exposure condition. However, comparisons should be made only between the densities obtained at one temperature, since only the films exposed at the same temperature were developed simultaneously.

The table also lists the photographic sensitivities relative to the sensitivity of the controls for all exposure conditions. ${ }^{2}$ At $5.5^{\circ} \mathrm{C}$ all sensitivities but those obtained at 98.3 percent relative humidity were within 10 percent of the values for the controls. However, at 98.3 percent relative humidity, the sensitivity was considerably lower. At this high humidity, the film exposed in a polyethylene bag to $0.25 r$ reached the same density as the film exposed to $1.0 \mathrm{r}$ in a bare packet. The 12-percent difference between the sensitivity of the controls and that obtained at 98.3 percent relative humidity with the film packets inside the polyethylene bags may be real, inasmuch as polyethylene is not entirely impermeable to water vapor.

2 Photographic sensitivity is here defined as the reciprocal of the exposure in $r$ required for a given density. The sensitivity values used for the tables are averages of the sensitivities determined at the density levels 0.2 and 0.5 .
At $19.8{ }^{\circ} \mathrm{C}$, the influence of high humidity was even more pronounced. Here, $0.5 r$ given to a film in a bare packet in an atmosphere of 97.2 percent relative humidity produced no measurable density above background, while at lower relative humidities the bare films showed a tendency to fog. The sensitivity of the films exposed in polyethylene-enclosed packets was not significantly different from that of the control.

At $32.5{ }^{\circ} \mathrm{C}$, there was a significant increase in the sensitivity of all films, as much as 30 percent for films protected from atmospheric changes. This was to be expected on the basis of the kinetics of the photographic process [7]. However, superimposed on this effect was, in the case of the bare packets, the effect of the varying atmospheric conditions. As a result, the films exposed in bare packets at relative humidities up to 75.6 percent showed an additional sensitivity increase of up to 15 percent. At a relative humidity of 96.5 percent, the films were tightly stuck to adjacent films contained in the same packets. During the process of separation, they were damaged considerably. The undamaged portions of the exposed films were fogged to a degree that made evaluation impossible. The density of the corresponding unexposed film, although higher than that of the film in the protected packet, was measurable. The density of the heated, unexposed film from the packet protected by polyethylene was not appreciably higher than that of the unexposed control film, which had been kept at room temperature.

\section{Conclusions}

Regardless of temperature, bare film packets cannot be used for satisfactory personnel dosimetry in areas where prolonged exposure to relative humidities close to a hundred percent are expected. Such high relative humidities cause physical damage to the film packets; moreover, at low temperatures,

Change in film response with temperature and relative humidity

\begin{tabular}{|c|c|c|c|c|c|c|c|c|c|c|c|}
\hline \multirow{3}{*}{ Temperature } & \multirow{3}{*}{$\begin{array}{l}\text { Relative } \\
\text { humidity }\end{array}$} & \multicolumn{8}{|c|}{ Net density for exposure of the jars to } & \multirow{2}{*}{\multicolumn{2}{|c|}{ Relative sensitivity }} \\
\hline & & \multicolumn{2}{|c|}{$0.10 r$} & \multicolumn{2}{|c|}{$0.25 r$} & \multicolumn{2}{|c|}{$0.50 r$} & \multicolumn{2}{|c|}{$1.00 r$} & & \\
\hline & & Bare & Plastic & Bare & Plastic & Bare & Plastic & Bare & Plastic & Bare & Plastic \\
\hline $5.5 \pm 3.5 \ldots$ & $\begin{array}{c}\% \\
13.9 \pm 1 \\
34.5 \pm 2 \\
75.1 \pm 0.6 \\
98.3 \pm .7 \\
\end{array}$ & $\begin{array}{r}0.02 \\
.03 \\
.03 \\
a 0 \\
\end{array}$ & $\begin{array}{r}0.04 \\
.03 \\
.03 \\
.02 \\
.03\end{array}$ & $\begin{array}{r}0.08 \\
.10 \\
.09 \\
-a 0\end{array}$ & $\begin{array}{r}0.09 \\
.10 \\
.09 \\
.09 \\
.09\end{array}$ & $\begin{array}{r}0.22 \\
.23 \\
.21 \\
a .02 \\
- \\
\end{array}$ & $\begin{array}{r}0.22 \\
.23 \\
.21 \\
.19 \\
. .22\end{array}$ & $\begin{array}{c}0.46 \\
.44 \\
.45 \\
a .09 \\
- \\
\end{array}$ & $\begin{array}{r}0.43 \\
.44 \\
.45 \\
.40 \\
. .46\end{array}$ & $\begin{array}{r}1.00 \\
.98 \\
.96 \\
\text { very low } \\
\end{array}$ & $\begin{array}{r}1.05 \\
.98 \\
.96 \\
.88 \\
\cdot 1.00\end{array}$ \\
\hline $19.8 \pm 0.5 \ldots$ & $\begin{array}{r}12.4 \pm 0.5 \\
33.5 \pm .5 \\
75.5 \pm .6 \\
97.2 \pm .5 \\
\end{array}$ & $\begin{array}{r}0.03 \\
.03 \\
.03 \\
a 0^{0} \\
\end{array}$ & $\begin{array}{r}0.03 \\
.03 \\
.03 \\
.03 \\
.03 \\
\end{array}$ & $\begin{array}{r}0.10 \\
.08 \\
.10 \\
a 0 \\
\end{array}$ & $\begin{array}{r}0.08 \\
.07 \\
.08 \\
.09 \\
c .07 \\
\end{array}$ & $\begin{array}{r}0.19 \\
.16 \\
.21 \\
0 . \\
\end{array}$ & $\begin{array}{r}0.16 \\
.15 \\
.18 \\
.17 \\
.17 \\
\end{array}$ & \begin{tabular}{|c|}
0.42 \\
.37 \\
.44 \\
$a .025$ \\
- \\
\end{tabular} & $\begin{array}{r}0.37 \\
.35 \\
.39 \\
.38 \\
\odot .38 \\
\end{array}$ & $\begin{array}{r}1.11 \\
1.00 \\
1.16 \\
\text { very low } \\
\end{array}$ & $\begin{array}{r}0.98 \\
.93 \\
1.02 \\
1.02 \\
\text { c1.00 } \\
\end{array}$ \\
\hline $32.5 \pm 1$ & $\begin{array}{l}11.7 \pm 0.5 \\
32.6 \pm .5 \\
75.6 \pm .7 \\
96.5 \pm .5\end{array}$ & $\begin{array}{r}0.06 \\
.04 \\
.06 \\
a 1.70 \\
\end{array}$ & $\begin{array}{r}0.03 \\
.04 \\
.03 \\
.06 \\
.02\end{array}$ & $\begin{array}{r}0.12 \\
.12 \\
.13 \\
a 1.68 \\
\end{array}$ & $\begin{array}{r}0.10 \\
.12 \\
.08 \\
.12 \\
.08\end{array}$ & $\begin{array}{r}0.27 \\
.21 \\
.26 \\
a 1.75 \\
-\end{array}$ & $\begin{array}{r}0.23 \\
.21 \\
.20 \\
.22 \\
\text { c. } 18\end{array}$ & $\begin{array}{r}0.54 \\
.44 \\
.49 \\
a 1.85 \\
- \\
-0-\end{array}$ & $\begin{array}{r}0.49 \\
.44 \\
.40 \\
.44 \\
\text { c. } 37\end{array}$ & 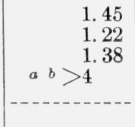 & $\begin{array}{r}1.29 \\
1.22 \\
1.07 \\
1.22 \\
\text { c1.00 }\end{array}$ \\
\hline
\end{tabular}

a The films stuck to adjacent films during exposure and had to be forced apart with a knife.

b Numerical evaluation impossible.

c Controls, exposed at laboratory temperature in dry jars. 
they produce excessive fading of the latent image and, at high temperatures, are the cause of emulsion fogging.

Personnel badge calibrations are usually made at normal laboratory temperatures, regardless of the ambient temperatures at which the personnel badges are to be used. When the temperatures are higher during use, one expects the personnel exposures to be overestimated. This error is less when the film packets that are to be used in the personnel badges are sealed in polyethylene bags. Thus, although polyethylene is not completely impermeable to water vapor, it does provide a considerable measure of protection to photographic film exposed under conditions of excessive atmospheric humidity.

\section{References}

[1] See, for instance, P. Demers, Les émulsions nucléaires, principes et applications, Ionographie, pp. 186-194, Les Presses Universitaires de Montréal (1958).

[2] W. L. MeLaughlin, M. Ehrlich, Nucleonics 12, 34-36 (1954).

[3] C. A. Ziegler, D. J. Chleck, Health Physics 4, 32-34 (1960).

[4] Y. Tomoda, N. Nakamura, J. Soc. Sci. Phot. Japan, 21, $16-19$ (1958).

[5] Y. Tomoda, J. Soc. Sci. Phot. Japan, 22, 12-17 (1959); see also abstract in Phot. Sci. and Eng. 4, 59 (1960).

[6] A. Wexler, S. Hasegawa, J. Research NBS 53, 19-26 (1954).

[7] For the influence of temperature on the latent image formed by X-rays, see, for instance, M. Ehrlich, Photographic Dosimetry of $\mathrm{X}$ - and Gamma Rays, NBS Handbook 57 (1954).

(Paper 65C3-72) 